\title{
Editorial
}

\section{Occupational bladder cancer and the hospital clinician}

A urological surgeon was, in 1895 , the first person to identify the hazard of occupational bladder cancer in dye workers' and so it might be thought that the hospital clinic would have thrown up more leads for fruitful epidemiological research by now, given the vast expansion of the chemical industry and the huge number of chemical compounds in regular use as compared with Rehn's time. The British Association of Urological Surgeons (BAUS) has also been concerned that its members may be missing occupational causes of cancer in their patients and first published some guidance on the subject in 1961. Now they have published a revised guide in the hope that urologists will take a greater interest in the possible aetiological agents that may come to light from the occupational histories of their patients. ${ }^{2}$ Apart from the possibility of uncovering new occupational causes of bladder cancer there is ample evidence that many patients suffering from the effects of exposure to the well known aromatic amines 2-naphthylamine and benzidine have failed to be alerted to the nature of their disease and consequently have missed out on compensation. The problem has been exacerbated by the economic recession in that some firms have gone out of business leaving workers who have been exposed in the past without organised urinary cytology (a screening procedure of doubtful benefit ${ }^{3}$ but which could be continued through the general practitioner), whereas some other firms may have decided that the risk of these earlier exposures is now over, even though cases are expected to occur at least until the end of the century.

Where should the urologist turn for advice when presented with a patient with a complex and suggestive occupational history? The official government body in the United Kingdom is the Employment Medical
Advisory Service of the Health \& Safety Executive but many medical practitioners continue to be unaware of its clinical advisory role. It does not involve itself in compensation, however. Although a new development has been the growth of consultant posts in occupational medicine in the NHS the number of these specialists is still small and services seem to be developing on a district rather than regional basis. Nevertheless, where these consultants exist rapport badly needs to be established with their urologist colleagues. Wallace suggests the setting up of an independent advisory unit. ${ }^{4}$

Occupational carcinogens will continue to be slowly identified through a combination of laboratory, epidemiological, and clinical means. The BAUS has performed an important service to its members in this latest publication and its accompanying review, ${ }^{4}$ but it will not be enough unless occupational physicians are also able to respond to its message.

\section{University of Cambridge Clinical School, Cambridge CB2 $2 Q Q$.}

\section{P J BAXTER}

\section{References}

1 Rehn L. Blasengeschwölste bei Fuchsin-Arbeitern. Archiv fur Klinische Chirurgie 1895;50:588-600.

2 British Association of Urological Surgeons Subcommittee on industrial bladder cancer. Occupational bladder cancer: a guide for clinicians. Br J Urol 1988;61:183-91.

3 Jacobs R. A review of the effectiveness of urinary cytology as a screening technique for occupational bladder cancer. $J$ Soc Occup Med 1987;37:24-6.

4 Wallace DMA. Occupational urothelial cancer. $B r J$ Urol 1988;61:175-82. 